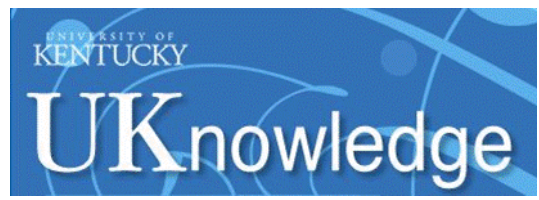

University of Kentucky

UKnowledge

\title{
Technical Considerations in Revision Anterior Cruciate Ligament Reconstruction for Operative Techniques in Orthopaedics
}

\author{
Jeremy M. Burnham \\ University of Pittsburgh \\ Elmar Herbst \\ University of Pittsburgh \\ Thierry Pauyo \\ University of Pittsburgh \\ Thomas Pfeiffer \\ University of Pittsburgh \\ Darren L. Johnson \\ University of Kentucky, dljohns@uky.edu
}

See next page for additional authors

Follow this and additional works at: https://uknowledge.uky.edu/orthopaedicsurgery_facpub

Part of the Orthopedics Commons, Sports Sciences Commons, and the Surgery Commons

Right click to open a feedback form in a new tab to let us know how this document benefits you.

\section{Repository Citation}

Burnham, Jeremy M.; Herbst, Elmar; Pauyo, Thierry; Pfeiffer, Thomas; Johnson, Darren L.; Fu, Freddie H.; and Musahl, Volker, "Technical Considerations in Revision Anterior Cruciate Ligament Reconstruction for Operative Techniques in Orthopaedics" (2017). Orthopaedic Surgery and Sports Medicine Faculty Publications. 17.

https://uknowledge.uky.edu/orthopaedicsurgery_facpub/17

This Article is brought to you for free and open access by the Orthopaedic Surgery and Sports Medicine at UKnowledge. It has been accepted for inclusion in Orthopaedic Surgery and Sports Medicine Faculty Publications by an authorized administrator of UKnowledge. For more information, please contact UKnowledge@lsv.uky.edu. 


\section{Technical Considerations in Revision Anterior Cruciate Ligament Reconstruction for Operative Techniques in Orthopaedics}

\section{Digital Object Identifier (DOI)}

https://doi.org/10.1053/j.oto.2017.01.012

\section{Notes/Citation Information}

Published in Operative Techniques in Orthopaedics, v. 27, issue 1, p. 63-69.

(C) 2017 Elsevier Inc. All rights reserved.

This manuscript version is made available under the CC-BY-NC-ND 4.0 license

https://creativecommons.org/licenses/by-nc-nd/4.0/.

The document available for download is the author's post-peer-review final draft of the article.

Authors

Jeremy M. Burnham, Elmar Herbst, Thierry Pauyo, Thomas Pfeiffer, Darren L. Johnson, Freddie H. Fu, and Volker Musahl 


\title{
Technical Considerations in Revision Anterior Cruciate Ligament (ACL) Reconstruction for Operative Techniques in Orthopaedics
}

\author{
Jeremy M. Burnham, MD ${ }^{1}$, Elmar Herbst, MD¹, Thierry Pauyo, MD¹, Thomas Pfeiffer, MD¹, \\ Darren L. Johnson, MD², Freddie H. Fu, MD¹, and Volker MusahI, MD1 \\ ${ }^{1}$ Department of Orthopaedic Surgery, UPMC Center for Sports Medicine, University of Pittsburgh, \\ 3200 S Water Street, Pittsburgh, PA 15203, USA \\ ${ }^{2}$ Department of Orthopaedic Surgery and Sports Medicine, University of Kentucky Medical \\ Center, 740 S. Limestone, K401, Lexington, KY 40536 USA
}

\begin{abstract}
As the incidence of anterior cruciate ligament (ACL) reconstruction continues to increase, the rate of revision surgery continues to climb. Revision surgery has inherent challenges that must be addressed in order to achieve successful results. The cause of the primary ACL reconstruction failure should be determined, and careful preoperative planning should be performed to address the cause(s) of failure. Each patient undergoing revision surgery should undergo a thorough history and physical examination, receive full length alignment radiographs, lateral radiographs, 45-degree flexion weight-bearing postero-anterior radiographs, and patellofemoral radiographs. 3dimensional computed topography (CT) scan should be performed to assess tunnel position and widening. Magnetic resonance imaging (MRI) should be used to assess for intra-articular soft tissue pathology. Meniscal tears, meniscal deficiency, anterolateral capsule injuries, bony morphology, age, activity level, connective tissue diseases, infection, graft choice, and tunnel position can all impact the success of ACL reconstruction surgery. Meniscal lesions should be repaired, and in cases of persistent rotatory instability, extra-articular procedures may be indicated. Furthermore, osteotomies may be needed to correct malalignment or excess posterior tibial slope. Depending on the placement and condition of the original femoral and tibial tunnels, revision surgery may be performed in a single procedure or in a staged manner. In most cases, the surgery can be performed in one procedure. Regardless, the surgeon must communicate with the patient openly regarding the implications of revision ACL surgery and the treatment plan should be developed in a shared fashion between the surgeon and the patient.
\end{abstract}

Address correspondence to: Volker Musahl, MD, Department of Orthopaedic Surgery, UPMC Center for Sports Medicine, University of Pittsburgh, 3200 S Water Street, Pittsburgh, PA 15203, USA, Phone number: +1 (412) 432-3600, Fax number: +1 (412) 687-3724, musahlv@upmc.edu.

Publisher's Disclaimer: This is a PDF file of an unedited manuscript that has been accepted for publication. As a service to our customers we are providing this early version of the manuscript. The manuscript will undergo copyediting, typesetting, and review of the resulting proof before it is published in its final citable form. Please note that during the production process errors may be discovered which could affect the content, and all legal disclaimers that apply to the journal pertain. 


\section{Background}

As the incidence of anterior cruciate ligament (ACL) reconstruction continues to increase, ${ }^{1,2}$ the rate of revision surgery continues to climb. Despite technical and rehabilitation advances in primary ACL surgery, the rate of re-tear remains higher than desired. ${ }^{3-6}$ In fact, some of the highest risk groups have been reported to have a $34 \%$ re-tear rate after ACL reconstruction, ${ }^{7}$ and half of these failures occur within 12 months after surgery. ${ }^{8}$ Age is an important risk factor for re-tear, with a recent registry study demonstrating a nearly 8 -fold increase in re-tear risk for patients $<21$ years of age as compared to those $>40$ years of age. ${ }^{9}$ In fact, not only is the ispsilateral side at risk of tear after ACL reconstruction, but many studies have shown a similar or even higher risk of ACL tear on the contralateral side. ${ }^{8,10}$ Similarly, the return to play rate is lower after revision ACL reconstruction compared to primary surgery. ${ }^{11}$

Failure of ACL reconstruction can have significant implications for the health of the knee. Data from the Multicenter Orthopedic Outcomes Network (MOON) and Multicenter ACL Revision Study (MARS) groups demonstrated that patients undergoing revision ACL reconstruction have a 1.7 times greater risk of Outerbridge grade 3 or 4 patellofemoral or lateral compartment cartilaginous lesions than those undergoing primary ACL reconstruction. ${ }^{12,13}$ Similarly, Trojani et al. reported that the cumulative incidence of meniscal tears increases with each ACL surgery, ${ }^{14}$ and Chen et al. reported a greater incidence of medial and patellofemoral compartment chondral damage in patients undergoing multiple revision surgeries as compared to those undergoing only one revision. ${ }^{15}$ Additional data from the MARS group has shown that $90 \%$ of patients undergoing revision ACL reconstruction have meniscal or chondral damage at the time of revision surgery, ${ }^{16}$ although data from the Danish ACL registry only reported cartilage damange in $31 \%$ of revision cases. ${ }^{17}$ Patient-reported outcomes and patient activity levels have also been shown to be worse after revision ACL reconstruction compared to primary ACL reconstruction. ${ }^{18}$

\section{Factors Contributing to Primary ACL Reconstruction Failure}

While the reasons for failure of primary ACL reconstruction can be multifactorial, numerous studies have reported on contributing factors. ${ }^{19}, 12,20-22,16,15,9,23,24$ Understanding the causes of primary ACL reconstruction is necessary to perform successful revision surgery. Chen et al. reported that the most common reason for failure in ACL reconstruction cases requiring a single revision was due to the patient sustaining some type of traumatic event leading to graft tear. However, when cases requiring multiple revisions were examined, technical failure was cited as the most common risk factor for revision. ${ }^{21}$

Femoral tunnel malposition has been repeatedly identified as the most common technical error in ACL reconstruction. Trojani et al. reported that anterior positioning of the femoral tunnel was responsible for failure in $36 \%$ of revision cases. ${ }^{14}$ Morgan et al. examined the MARS data and reported that femoral tunnel malposition was a contributing factor to failure in $47 \%$ of cases and the only cited reason for failure in $25 \%$ of cases. ${ }^{25}$ 
Graft choice has also been shown to play an important role in ACL reconstruction success. ${ }^{26-28}$ Numerous studies have shown an exceedingly increased rate of failure in young patients reconstructed with allograft. Engelman et al. reported a 4.4 hazard ratio in allograft as compared to autograft patients (age 11-18). ${ }^{28}$ Similarly, Kaeding et al. reported a 4 times greater risk of graft failure with allograft compared to autograft. ${ }^{26}$ In addition, $\mathrm{Li}$ et al. reported greater serum inflammatory marker levels and greater anteroposterior knee instability in allograft patients compared to autograft or hybrid patients. ${ }^{29} \mathrm{In}$ fact, allograft is not considered within the standard of care for most young, active patients undergoing ACL reconstruction.

Graft size has been associated with risk of failure. Magnussen et al. retrospectively examined outcomes among hamstring autograft patients and reported that a graft diameter of $8 \mathrm{~mm}$ or less in young active patients was resulted in an increased re-tear risk. ${ }^{15}$ Conte et al. performed a systematic review and stated that hamstring autograft sizes of $8 \mathrm{~mm}$ or more reduced the failure rate. Spragg et al. examined patients in the Kaiser Permanente ACL revision registry and reported a 0.82 times lower risk of revision for every $0.5 \mathrm{~mm}$ increase in hamstring autograft diameter in patients with a median age of 17 years. ${ }^{30}$ Interestingly, Mariscalco et al. reported lower patient-reported outcomes with smaller diameter grafts. ${ }^{31}$ However, it is important that graft size be individualized according to the patient, as increased graft sizes in patients with a small notch or smaller bony morphology may result in an increased re-tear rate. ${ }^{32,33}$

Numerous other factors can contribute to primary ACL reconstruction failure. While some autograft types have been promoted as superior to others, studies have failed to show consistent differences in survival between the most commonly utilized autografts (hamstring, quadriceps tendon, patellar tendon). ${ }^{34-38}$ However, recent data from the Danish and Norwegian Knee Registries suggests that there may be a higher failure rate with hamstring compared to patellar tendon autografts. ${ }^{39,40}$ Anatomic ACL reconstruction has been widely shown to result in improved knee joint kinematics, resulting in better knee health, but has been also reported to be associated with an increased re-tear rate due to increased in-situ graft forces. ${ }^{41-44}$ Furthermore, graft fixation methods, time to return to sports, activity level, trunk and lower extremity muscle function, generalized ligamentous laxity, age, gender, presence of associated injuries such as under-appreciated meniscal tears or anterolateral rotatory instability, and bony morphology of the knee and extremity can all contribute to graft survival in primary ACL reconstruction. ${ }^{45,46,21,47,14,48,49}$

\section{Technical Considerations for Revision ACL Reconstruction Surgery}

\section{Preoperative Planning}

Preoperative planning is crucial to ensure successful revision surgery. A thorough history should be obtained, with a special emphasis on activity level, mechanism of injury, and antecedent symptoms. ${ }^{50}$ The reason for failure of the primary reconstruction surgery must be determined in order to avoid the same outcome with revision surgery. ${ }^{20}$ The patient should also be queried for information regarding previous joint injuries, history of coagulation disorders, osteoporosis risk factors, and any history of generalized ligamentous laxity or connective tissue disorders. It is important to communicate openly with the patient about 
their post-surgical expectations and planned activity level, especially regarding return to competitive sports. ${ }^{20}$ The surgeon and patient should participate in shared-decision making when planning the next course of action.

Every patient should receive a thorough physical exam. Any signs of generalized ligamentous laxity or syndromic features should be noted. Alignment, range of motion, and muscle strength of the injured and contralateral extremity should be carefully examined. ${ }^{20}$ The knee should also be assessed for any signs of infection. The stability of the injured knee should be evaluated in the context of the uninjured knee, with the goal of surgery to restore the native stability. ${ }^{50}$

Preoperative imaging should consist of full-length alignment films to assess for coronal and sagittal plane malalignment. In some cases it may be necessary to address severe malaligntment in addition to reconstructing the ACL. In addition, lateral, 45-degree weightbearing flexion postero-anterior, and patellofemoral radiographs should be obtained to assess for arthritic changes. ${ }^{51,52}$ Computed topography (CT) imaging with 3D reconstruction should be obtained to assess the femoral and tibial tunnel positions and size. Magnetic resonance imaging (MRI) should be carefully reviewed for associated injuries such as meniscal tears, anterolateral capsule injuries, menisco-capsular separation, and additional ligamentous injuries. Assessment of bone bruise patterns can also provide insight into injury mechanisms. ${ }^{20}$ The patient should also undergo quantitative pivot shift testing to assess for the degree of rotatory instability (Figure 1) ${ }^{53,54}$ which can indicate additional injury including clinically relevant meniscal tears, anterolateral complex injuries, or underlying bony morphology consistent with rotatory instability. In these cases, additional procedures such as extra-articular tenodesis may be indicated.

Finally, the prior clinic and operative notes must be obtained and studied prior to surgery. It is imperative that the graft fixation types, and sites of fixation, be determined before the day of surgery. Many of these devices can require specialized tools for removal, and bone overgrowth, scar tissue, and implant migration can make removal of the old hardware even more difficult. The optimal time to decide on whether the old hardware needs to be removed, and what instruments may be needed for removal, is prior to the day of surgery.

\section{Single versus Two-Staged}

Depending on the existing tunnel locations and sizes, revision ACL reconstruction can be performed in a single or two-staged manner. In most cases, non-anatomic primary ACL reconstructions can be revised in a single revision surgery. Non-anatomic positioning of the graft in the index procedure often allows anatomic placement of new tunnels with ample space between the old and new tunnels (Figure 2). This can be especially advantageous in situations with difficult to remove hardware from the primary ACL reconstruction. If the initial tunnels have been placed in an anatomic or semi-anatomic position, single-stage surgery is still an option (Figure 3). ${ }^{55}$ Preoperative assessment of the CT scan can be helpful in measuring tunnel size and determining the feasibility of a single stage surgery in this instance. ${ }^{55}$ In general, the same tunnels can be reused if the tunnel diameter is less than $16 \mathrm{~mm}$. Tunnel diameters larger than this result in difficulties with graft fixation, stability, and healing. ${ }^{20,56}$ 
If the existing tunnels are anatomic with significant widening $(>16 \mathrm{~mm}$ diameter or more than $100 \%$ widening), a staged reconstruction may be required. ${ }^{55,56,20}$ In these cases, the bone grafting of the femoral tunnel, and occasionally the tibial tunnel, is performed in the first stage. Bone graft options include numerous different allograft and autograft choices. After sufficient healing time (usually around 3-4 months) and after imaging has demonstrated adequate bone consolidation, the second stage is performed with final revision graft placement. ${ }^{56}$ An alternative to staged reconstruction in these cases is to use an "overthe-top" femoral fixation technique, which provides anatomic positioning of the graft, while at the same time avoiding the existing tunnel. ${ }^{20}$

\section{Graft Choices}

Graft choices are similar to those used in primary surgery (patellar tendon, quadriceps tendon, hamstring). However, there are some instances that my required specialized grafts. For example, an Achilles allograft with a bone block may be advantageous in examples of a widened femoral or tibial tunnel. In these cases, the allograft bone block can be cut to the appropriate size to match the existing tunnel size. This is especially useful when the bone block is placed in a widened tibial tunnel and the soft tissue portion of the graft is fixed with an "over-the-top" technique on the femoral side. This technique also allows rotation of the bone block within the widened tunnel so that the tendinous portion of the graft most closely matches the anatomic position of the graft. Often, a widened tibial tunnel requires the bone block to be rotated so that the tendinous graft is positioned more anteriorly. It should also be noted that prior use of a specific autograft does not necessarily preclude harvesting from the same site for revision surgery. In some cases, quadriceps or patellar tendon regeneration is sufficient for re-use of these graft sites in revision surgery. Preoperative imaging is key to assess for this possibility prior to surgery.

\section{Additional Procedures}

The reason for failure of the primary ACL reconstruction should be carefully scrutinized. In some cases, additional procedures will be necessary to ensure success of the revision surgery. Meniscal tears can contribute to the rotatory stability of the knee and should be repaired if possible. ${ }^{49}$ Extreme meniscal insufficiency, such as that seen after subtotal menisectomy, may require a meniscal transplant (Figure 4). In addition, bony morphology should be assessed. Bony features such as increased posterior tibial slope and a deep lateral femoral notch have been associated with increased ACL injury risk and rotatory knee instability. ${ }^{57-61,23}$ In addition, stereo fluoroscopy at our institution has demonstrated that posterior tibial slope correlates with knee kinematics in ACL reconstructed patients (Figure 5). ${ }^{23}$ In cases of excessive posterior tibial slope, an anterior closing wedge tibial osteotomy may be indicated. Similarly, patients with excessive varus malalignment may experience greater in-situ graft forces, ${ }^{62}$ and concomitant proximal tibial osteotomy may be needed. In addition, patients with anterolateral complex injuries may benefit from extra-articular tenodesis procedures, ${ }^{63-65}$ although the indications and risk factors for these procedures are not fully understood. ${ }^{66-68,49}$ 


\section{Conclusion}

In conclusion, revision ACL reconstruction is an increasingly common procedure with significant potential implications for the long-term health of the knee joint. Revision reconstruction is associated with inherent challenges that make thorough preoperative assessment and planning imperative to success of the procedure. The cause of failure of the index surgery must be vigorously sought out, and the surgeon must be diligent to correct whichever factors may have contributed to this initial failure. All contributions to rotatory knee stability must be assessed, and additional procedures may be needed to restore native knee stability. In addition, the patient should be counseled about the increased threat to overall knee health and reinjury that result from repeated ACL injury.

\section{References}

1. Buller LT, Best MJ, Baraga MG, Kaplan LD. Trends in Anterior Cruciate Ligament Reconstruction in the United States. Orthop J Sports Med. 2015; 3:2325967114563664. [PubMed: 26535368]

2. Mall NA, Chalmers PN, Moric M, et al. Incidence and trends of anterior cruciate ligament reconstruction in the United States. The American journal of sports medicine. 2014; 42:2363-2370. [PubMed: 25086064]

3. Wiggins AJ, Grandhi RK, Schneider DK, Stanfield D, Webster KE, Myer GD. Risk of Secondary Injury in Younger Athletes After Anterior Cruciate Ligament Reconstruction: A Systematic Review and Meta-analysis. The American journal of sports medicine. 2016; 44:1861-1876. [PubMed: 26772611]

4. Brophy RH, Schmitz L, Wright RW, et al. Return to play and future ACL injury risk after ACL reconstruction in soccer athletes from the Multicenter Orthopaedic Outcomes Network (MOON) group. The American journal of sports medicine. 2012; 40:2517-2522. [PubMed: 23002201]

5. Paterno MV, Rauh MJ, Schmitt LC, Ford KR, Hewett TE. Incidence of Second ACL Injuries 2 Years After Primary ACL Reconstruction and Return to Sport. The American journal of sports medicine. 2014; 42:1567-1573. [PubMed: 24753238]

6. Hettrich CM, Dunn WR, Reinke EK, Group M, Spindler KP. The rate of subsequent surgery and predictors after anterior cruciate ligament reconstruction: two- and 6-year follow-up results from a multicenter cohort. The American journal of sports medicine. 2013; 41:1534-1540. [PubMed: 23722056]

7. Allen MM, Pareek A, Krych AJ, et al. Are Female Soccer Players at an Increased Risk of Second Anterior Cruciate Ligament Injury Compared With Their Athletic Peers? The American journal of sports medicine. 2016

8. Webster KE, Feller JA, Leigh WB, Richmond AK. Younger patients are at increased risk for graft rupture and contralateral injury after anterior cruciate ligament reconstruction. The American journal of sports medicine. 2014; 42:641-647. [PubMed: 24451111]

9. Maletis GB, Chen J, Inacio MC, Funahashi TT. Age-Related Risk Factors for Revision Anterior Cruciate Ligament Reconstruction: A Cohort Study of 21,304 Patients From the Kaiser Permanente Anterior Cruciate Ligament Registry. The American journal of sports medicine. 2016; 44:331-336. [PubMed: 26637284]

10. Wright RW, Magnussen RA, Dunn WR, Spindler KP. Ipsilateral graft and contralateral ACL rupture at five years or more following ACL reconstruction: a systematic review. The Journal of bone and joint surgery American volume. 2011; 93:1159-1165. [PubMed: 21776554]

11. Reinhardt KR, Hammoud S, Bowers AL, Umunna BP, Cordasco FA. Revision ACL Reconstruction in Skeletally Mature Athletes Younger Than 18 Years. Clinical orthopaedics and related research. 2012; 470:835-842. [PubMed: 21739323]

12. Borchers JR, Kaeding CC, Pedroza AD, et al. Intra-articular findings in primary and revision anterior cruciate ligament reconstruction surgery: a comparison of the MOON and MARS study groups. The American journal of sports medicine. 2011; 39:1889-1893. [PubMed: 21646434] 
13. Cameron ML, Briggs KK, Steadman JR. Reproducibility and reliability of the outerbridge classification for grading chondral lesions of the knee arthroscopically. The American journal of sports medicine. 2003; 31:83-86. [PubMed: 12531763]

14. Trojani C, Sbihi A, Djian P, et al. Causes for failure of ACL reconstruction and influence of meniscectomies after revision. Knee surgery, sports traumatology, arthroscopy: official journal of the ESSKA. 2011; 19:196-201.

15. Magnussen RA, Lawrence JT, West RL, Toth AP, Taylor DC, Garrett WE. Graft size and patient age are predictors of early revision after anterior cruciate ligament reconstruction with hamstring autograft. Arthroscopy. 2012; 28:526-531. [PubMed: 22305299]

16. Group M, Wright RW, Huston LJ, et al. Descriptive epidemiology of the Multicenter ACL Revision Study (MARS) cohort. The American journal of sports medicine. 2010; 38:1979-1986. [PubMed: 20889962]

17. Lind M, Menhert F, Pedersen AB. The first results from the Danish ACL reconstruction registry: epidemiologic and 2 year follow-up results from 5,818 knee ligament reconstructions. Knee surgery, sports traumatology, arthroscopy: official journal of the ESSKA. 2009; 17:117-124.

18. Wright R, Spindler K, Huston L, et al. Revision ACL reconstruction outcomes: MOON cohort. J Knee Surg. 2011; 24:289-294. [PubMed: 22303759]

19. Bjornsson H, Andernord D, Desai N, et al. No difference in revision rates between single- and double-bundle anterior cruciate ligament reconstruction: a comparative study of 16,791 patients from the Swedish national knee ligament register. Arthroscopy. 2015; 31:659-664. [PubMed: 25618489]

20. Cheatham SA, Johnson DL. Anticipating problems unique to revision ACL surgery. Sports medicine and arthroscopy review. 2013; 21:129-134. [PubMed: 23649161]

21. Chen JL, Allen CR, Stephens TE, et al. Differences in mechanisms of failure, intraoperative findings, and surgical characteristics between single- and multiple-revision ACL reconstructions: a MARS cohort study. The American journal of sports medicine. 2013; 41:1571-1578. [PubMed: 23698386]

22. Fauno P, Rahr-Wagner L, Lind M. Risk for Revision After Anterior Cruciate Ligament Reconstruction Is Higher Among Adolescents: Results From the Danish Registry of Knee Ligament Reconstruction. Orthop J Sports Med. 2014; 2:2325967114552405. [PubMed: 26535272]

23. Rahnemai-Azar AA, Abebe ES, Johnson P, et al. Increased lateral tibial slope predicts high-grade rotatory knee laxity pre-operatively in ACL reconstruction. Knee surgery, sports traumatology, arthroscopy: official journal of the ESSKA. 2016

24. Rahr-Wagner L, Thillemann TM, Pedersen AB, Lind MC. Increased risk of revision after anteromedial compared with transtibial drilling of the femoral tunnel during primary anterior cruciate ligament reconstruction: results from the Danish Knee Ligament Reconstruction Register. Arthroscopy. 2013; 29:98-105. [PubMed: 23276417]

25. Morgan JA, Dahm D, Levy B, Stuart MJ, Group MS. Femoral tunnel malposition in ACL revision reconstruction. J Knee Surg. 2012; 25:361-368. [PubMed: 23150344]

26. Kaeding CC, Aros B, Pedroza A, et al. Allograft Versus Autograft Anterior Cruciate Ligament Reconstruction: Predictors of Failure From a MOON Prospective Longitudinal Cohort. Sports health. 2011; 3:73-81. [PubMed: 23015994]

27. Kaeding CC, Pedroza AD, Reinke EK, Huston LJ, Spindler KP. Consortium M. Risk Factors and Predictors of Subsequent ACL Injury in Either Knee After ACL Reconstruction: Prospective Analysis of 2488 Primary ACL Reconstructions From the MOON Cohort. The American journal of sports medicine. 2015; 43:1583-1590. [PubMed: 25899429]

28. Engelman GH, Carry PM, Hitt KG, Polousky JD, Vidal AF. Comparison of allograft versus autograft anterior cruciate ligament reconstruction graft survival in an active adolescent cohort. The American journal of sports medicine. 2014; 42:2311-2318. [PubMed: 25081312]

29. Li J, Wang J, Li Y, Shao D, You X, Shen Y. A Prospective Randomized Study of Anterior Cruciate Ligament Reconstruction With Autograft, gamma-Irradiated Allograft, and Hybrid Graft. Arthroscopy. 2015; 31:1296-1302. [PubMed: 25891223] 
30. Spragg L, Chen J, Mirzayan R, Love R, Maletis G. The Effect of Autologous Hamstring Graft Diameter on the Likelihood for Revision of Anterior Cruciate Ligament Reconstruction. The American journal of sports medicine. 2016; 44:1475-1481. [PubMed: 27002103]

31. Mariscalco MW, Flanigan DC, Mitchell J, et al. The influence of hamstring autograft size on patient-reported outcomes and risk of revision after anterior cruciate ligament reconstruction: a Multicenter Orthopaedic Outcomes Network (MOON) Cohort Study. Arthroscopy. 2013; 29:19481953. [PubMed: 24140144]

32. van Eck CF, Martins CA, Vyas SM, Celentano U, van Dijk CN, Fu FH. Femoral intercondylar notch shape and dimensions in ACL-injured patients. Knee surgery, sports traumatology, arthroscopy: official journal of the ESSKA. 2010; 18:1257-1262.

33. Gormeli CA, Gormeli G, Ozturk BY, et al. The effect of the intercondylar notch width index on anterior cruciate ligament injuries. a study on groups with unilateral and bilateral ACL injury. Acta Orthop Belg. 2015; 81:240-244. [PubMed: 26280962]

34. Gabler CM, Jacobs CA, Howard JS, Mattacola CG, Johnson DL. Comparison of Graft Failure Rate Between Autografts Placed via an Anatomic Anterior Cruciate Ligament Reconstruction Technique: A Systematic Review, Meta-analysis, and Meta-regression. The American journal of sports medicine. 2015

35. Genuario JW, Faucett SC, Boublik M, Schlegel TF. A cost-effectiveness analysis comparing 3 anterior cruciate ligament graft types: bone-patellar tendon-bone autograft, hamstring autograft, and allograft. The American journal of sports medicine. 2012; 40:307-314. [PubMed: 22085728]

36. Goldblatt JP, Fitzsimmons SE, Balk E, Richmond JC. Reconstruction of the anterior cruciate ligament: meta-analysis of patellar tendon versus hamstring tendon autograft. Arthroscopy. 2005; 21:791-803. [PubMed: 16012491]

37. Spindler KP. Anterior Cruciate Ligament Reconstruction Autograft Choice: Bone-Tendon-Bone Versus Hamstring: Does It Really Matter? A Systematic Review. American Journal of Sports Medicine. 2004; 32:1986-1995. [PubMed: 15572332]

38. Eriksson E. Patellar tendon or quadriceps tendon grafts for ACL reconstruction. Knee surgery, sports traumatology, arthroscopy: official journal of the ESSKA. 2007; 15:1283.

39. Persson A, Fjeldsgaard K, Gjertsen JE, et al. Increased risk of revision with hamstring tendon grafts compared with patellar tendon grafts after anterior cruciate ligament reconstruction: a study of 12,643 patients from the Norwegian Cruciate Ligament Registry, 2004-2012. The American journal of sports medicine. 2014; 42:285-291. [PubMed: 24322979]

40. Rahr-Wagner L, Thillemann TM, Pedersen AB, Lind M. Comparison of hamstring tendon and patellar tendon grafts in anterior cruciate ligament reconstruction in a nationwide population-based cohort study: results from the danish registry of knee ligament reconstruction. The American journal of sports medicine. 2014; 42:278-284. [PubMed: 24275859]

41. Araujo PH, Asai S, Pinto M, et al. ACL Graft Position Affects in Situ Graft Force Following ACL Reconstruction. The Journal of bone and joint surgery American volume. 2015; 97:1767-1773. [PubMed: 26537164]

42. Gabriel MT, Wong EK, Woo SL, Yagi M, Debski RE. Distribution of in situ forces in the anterior cruciate ligament in response to rotatory loads. Journal of orthopaedic research: official publication of the Orthopaedic Research Society. 2004; 22:85-89. [PubMed: 14656664]

43. Liu A, Sun M, Ma C, et al. Clinical outcomes of transtibial versus anteromedial drilling techniques to prepare the femoral tunnel during anterior cruciate ligament reconstruction. Knee surgery, sports traumatology, arthroscopy: official journal of the ESSKA. 2015

44. Chen Y, Chua KH, Singh A, et al. Outcome of Single-Bundle Hamstring Anterior Cruciate Ligament Reconstruction Using the Anteromedial Versus the Transtibial Technique: A Systematic Review and Meta-analysis. Arthroscopy. 2015; 31:1784-1794. [PubMed: 26354196]

45. Kamien PM, Hydrick JM, Replogle WH, Go LT, Barrett GR. Age, graft size, and Tegner activity level as predictors of failure in anterior cruciate ligament reconstruction with hamstring autograft. The American journal of sports medicine. 2013; 41:1808-1812. [PubMed: 23813800]

46. Crawford SN, Waterman BR, Lubowitz JH. Long-term failure of anterior cruciate ligament reconstruction. Arthroscopy. 2013; 29:1566-1571. [PubMed: 23820260] 
47. van Eck CF, Schkrohowsky JG, Working ZM, Irrgang JJ, Fu FH. Prospective analysis of failure rate and predictors of failure after anatomic anterior cruciate ligament reconstruction with allograft. The American journal of sports medicine. 2012; 40:800-807. [PubMed: 22238055]

48. Burnham JM, Yonz MC, Robertson KE, et al. Relationship of Hip and Trunk Muscle Function with Single Leg Step-Down Performance: Implications for Return to Play Screening and Rehabilitation. Physical Therapy in Sport. 2016; 22:66-73. [PubMed: 27592407]

49. Musahl V, Rahnemai-Azar AA, Costello J, et al. The Influence of Meniscal and Anterolateral Capsular Injury on Knee Laxity in Patients With Anterior Cruciate Ligament Injuries. The American journal of sports medicine. 2016

50. Hofbauer M, Muller B, Murawski CD, van Eck CF, Fu FH. The concept of individualized anatomic anterior cruciate ligament (ACL) reconstruction. Knee surgery, sports traumatology, arthroscopy: official journal of the ESSKA. 2014; 22:979-986.

51. Duncan ST, Khazzam MS, Burnham JM, Spindler KP, Dunn WR, Wright RW. Sensitivity of Standing Radiographs to Detect Knee Arthritis: A Systematic Review of Level I Studies. Arthroscopy. 2015; 31:321-328. [PubMed: 25312767]

52. Gossec L, Jordan JM, Mazzuca SA, et al. Comparative evaluation of three semi-quantitative radiographic grading techniques for knee osteoarthritis in terms of validity and reproducibility in 1759 X-rays: report of the OARSI-OMERACT task force. Osteoarthritis Cartilage. 2008; 16:742748. [PubMed: 18417373]

53. Musahl V, Griffith C, Irrgang JJ, et al. Validation of Quantitative Measures of Rotatory Knee Laxity. The American journal of sports medicine. 2016; 44:2393-2398. [PubMed: 27371547]

54. Ahlden M, Araujo P, Hoshino Y, et al. Clinical grading of the pivot shift test correlates best with tibial acceleration. Knee surgery, sports traumatology, arthroscopy: official journal of the ESSKA. 2012; 20:708-712.

55. van Eck CF, Schreiber VM, Liu TT, Fu FH. The anatomic approach to primary, revision and augmentation anterior cruciate ligament reconstruction. Knee surgery, sports traumatology, arthroscopy: official journal of the ESSKA. 2010; 18:1154-1163.

56. Maak TG, Voos JE, Wickiewicz TL, Warren RF. Tunnel widening in revision anterior cruciate ligament reconstruction. The Journal of the American Academy of Orthopaedic Surgeons. 2010; 18:695-706. [PubMed: 21041804]

57. Herbst E, Hoser C, Tecklenburg K, et al. The lateral femoral notch sign following ACL injury: frequency, morphology and relation to meniscal injury and sports activity. Knee surgery, sports traumatology, arthroscopy: official journal of the ESSKA. 2015; 23:2250-2258.

58. Nakauchi M, Kurosawa H, Kawakami A. Abnormal lateral notch in knees with anterior cruciate ligament injury. Journal of Orthopaedic Science. 2000; 5:92-95. [PubMed: 10982640]

59. Speer KP, Spritzer CE, Bassett FH 3rd, Feagin JA Jr, Garrett WE Jr. Osseous injury associated with acute tears of the anterior cruciate ligament. The American journal of sports medicine. 1992; 20:382-389. [PubMed: 1415878]

60. Cobby MJ, Schweitzer ME, Resnick D. The deep lateral femoral notch: an indirect sign of a torn anterior cruciate ligament. Radiology. 1992; 184:855-858. [PubMed: 1509079]

61. Rahnemai-Azar AA, Yaseen Z, van Eck CF, Irrgang JJ, Fu FH, Musahl V. Increased Lateral Tibial Plateau Slope Predisposes Male College Football Players to Anterior Cruciate Ligament Injury. The Journal of bone and joint surgery American volume. 2016; 98:1001-1006. [PubMed: 27307360]

62. Hinckel BB, Demange MK, Gobbi RG, Pecora JR, Camanho GL. The Effect of Mechanical Varus on Anterior Cruciate Ligament and Lateral Collateral Ligament Stress: Finite Element Analyses. Orthopedics. 2016; 39:e729-736. [PubMed: 27111082]

63. Lemaire M, Combelles F. Plastic repair with fascia lata for old tears of the anterior cruciate ligament (author's transl). Rev Chir Orthop Reparatrice Appar Mot. 1980; 66:523-525. [PubMed: 6451004]

64. Pernin J, Verdonk P, Si Selmi TA, Massin P, Neyret P. Long-term follow-up of 24. 5 years after intra-articular anterior cruciate ligament reconstruction with lateral extra-articular augmentation. The American journal of sports medicine. 2010; 38:1094-1102. [PubMed: 20305053] 
65. Marcacci M, Zaffagnini S, Iacono F, Neri MP, Loreti I, Petitto A. Arthroscopic intra- and extraarticular anterior cruciate ligament reconstruction with gracilis and semitendinosus tendons. Knee surgery, sports traumatology, arthroscopy: official journal of the ESSKA. 1998; 6:68-75.

66. Sonnery-Cottet B, Lutz C, Daggett M, et al. The Involvement of the Anterolateral Ligament in Rotational Control of the Knee. The American journal of sports medicine. 2016; 44:1209-1214. [PubMed: 26865395]

67. Song GY, Zhang H, Wang QQ, Zhang J, Li Y, Feng H. Risk Factors Associated With Grade 3 Pivot Shift After Acute Anterior Cruciate Ligament Injuries. The American journal of sports medicine. 2016; 44:362-369. [PubMed: 26620298]

68. Rahnemai-Azar AA, Miller RM, Guenther D, et al. Structural Properties of the Anterolateral Capsule and Iliotibial Band of the Knee. The American journal of sports medicine. 2016; 44:892897. [PubMed: 26811306] 


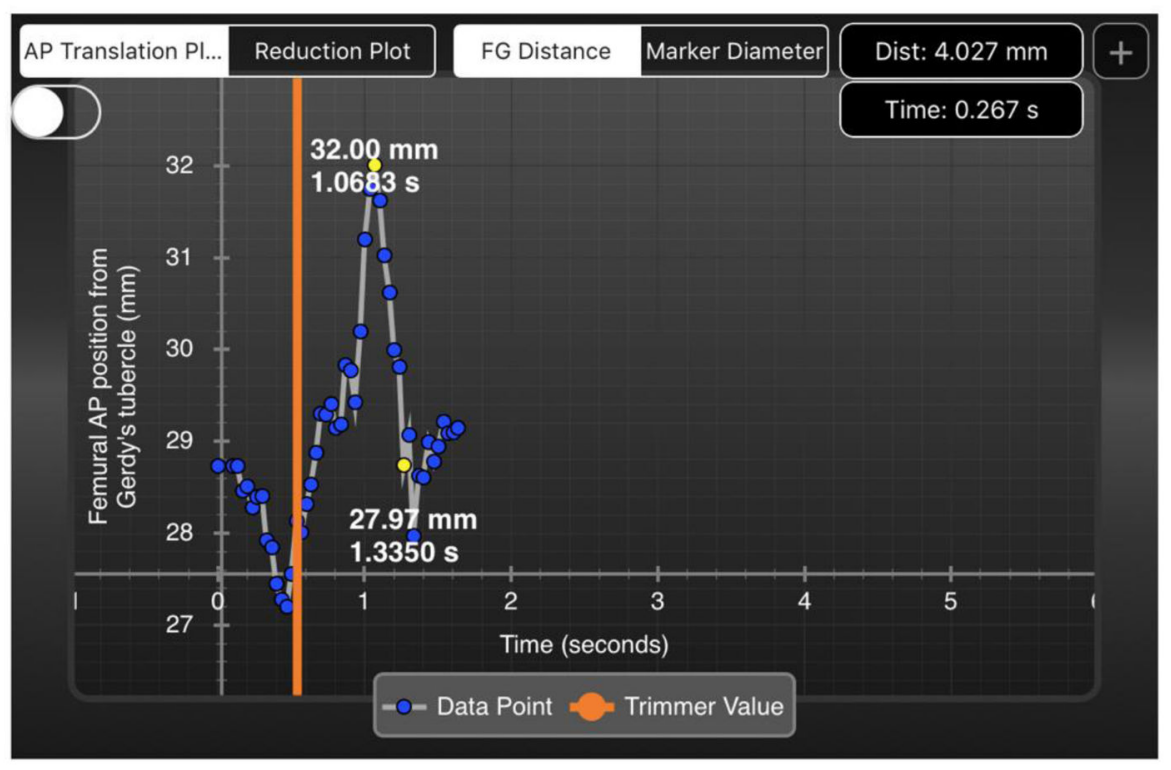

Figure 1. Quantitative Pivot Shift Measurement

An iPad Screenshot demonstrates a graphical representation of a quantitative pivot shift measurement. Surface markers (not shown) are placed on the lateral femoral epicondyle, Gerdy's tubercle, and the fibular head. The iPad video camera then records the pivot shift maneuver and calculates the lateral compartment translation. The $4.027 \mathrm{~mm}$ distance displaced in this figure is then multiplied by a factor of 3 (surface markers on the skin translate 3 times less during pivot shift than the actual bone) for a total of $12.081 \mathrm{~mm}$ of lateral tibial translation. 


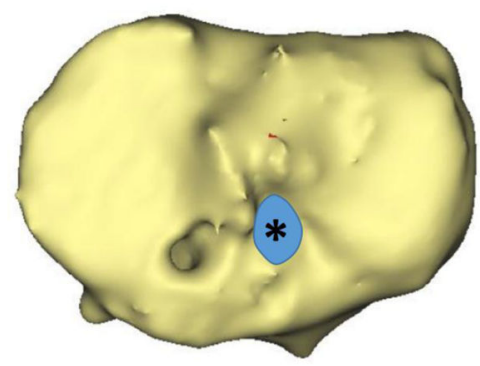

$A$

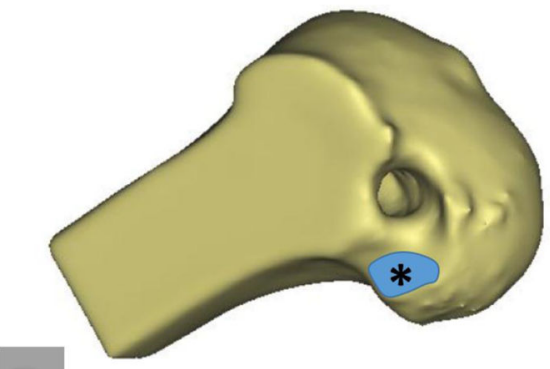

B

Figure 2. 3-Dimensional CT Scan for Tunnel Assessment

A 3D CT scan demonstrates the primary reconstruction tibial (A) and femoral tunnels (B).

An asterisk indicates the center of the actual ACL footprint, and the goal location of the new tunnels. In this case, the previous tunnels have been placed in a non-antomic position, and the revision can be performed utilizing completely new tunnels, with little risk of convergence of the pre-existing tunnels. 

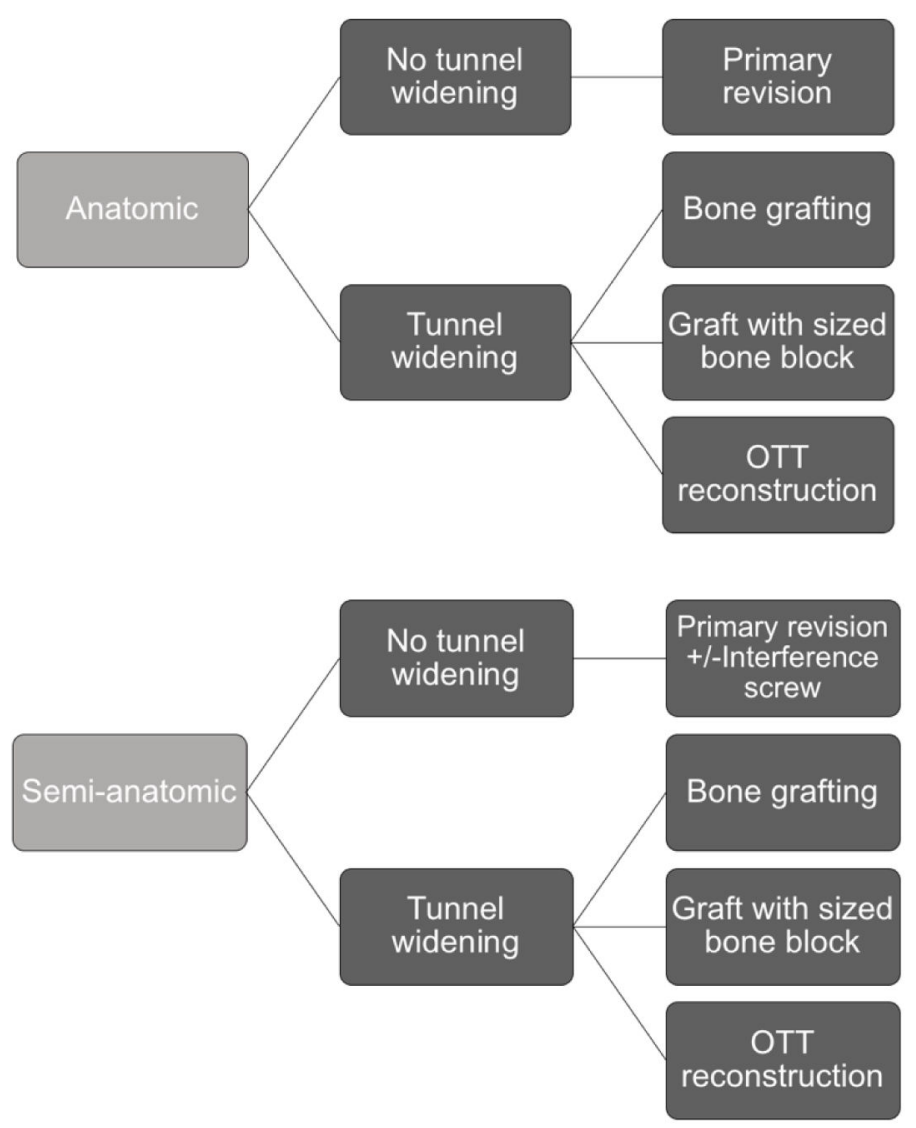

Figure 3. Algorithm for Staging of Revision ACL Reconstruction

When revising a previous ACL reconstruction which utilized anatomic tunnel positions, a primary single stage surgery can be performed if there is no excessive tunnel widening. If there is tunnel widening $>16 \mathrm{~mm}$, a staged procedure with bone grafting can be performed, a graft with a large bone block can be utilized, or the femoral fixation can be performed using the over-the-top technique. Similarly, if the tunnels are in a semi-anatomic position, alternative options may be indicated if tunnel widening is present. If the tunnels are in a completely non-anatomic position, revision surgery can often be performed utilizing completely new tunnels. 


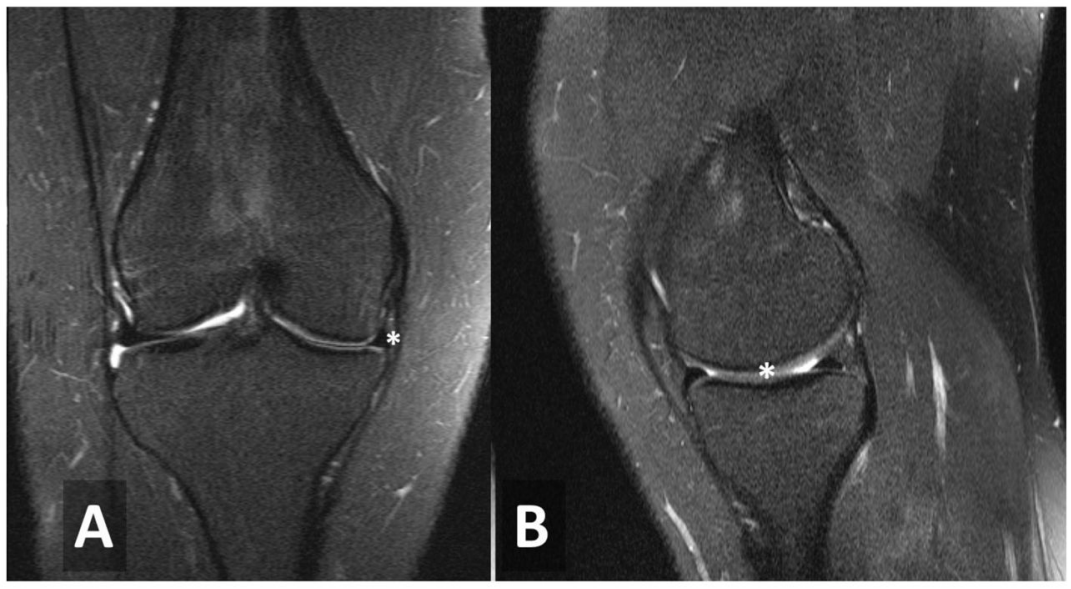

Figure 4. Magnetic Resonance Imaging Demonstrating Meniscal Insufficiency T2 magnetic resonance imaging (MRI) demonstrating significant medial meniscal deficiency. An asterisk is placed near the diminutive meniscus in the coronal (A) and sagittal (B) cuts. In the case of extreme meniscal deficiency, the meniscal allograft may be indicated in a an active patient with minimal arthritic changes. 


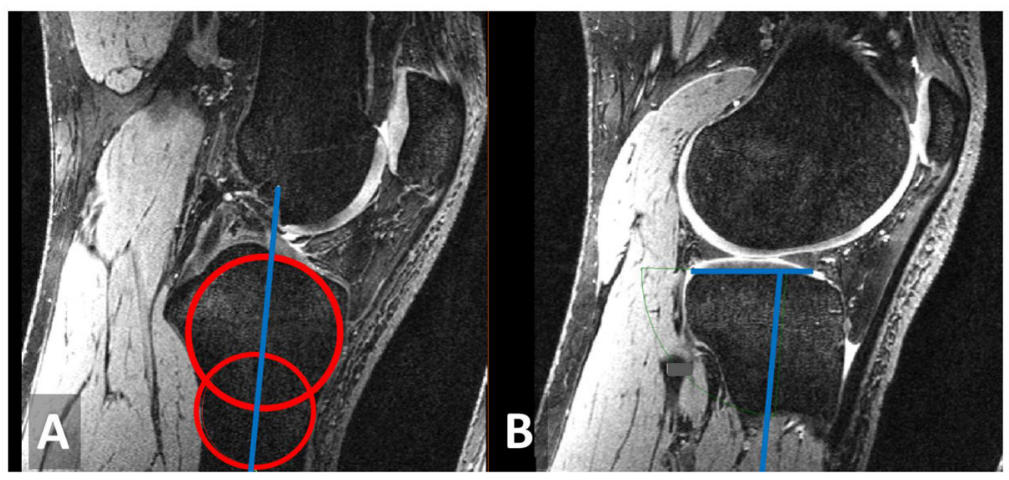

Figure 5. Technique for Measurement of Tibial Slope

Sagittal 1-Tesla magnetic resonance imaging (MRI) demonstrating the technique to measure posterior tibial slope. A) A line is drawn going through the center of concentric circles to localize the anatomic axis of the tibia. B) The angle between the anatomic tibial axis and the articular surface is measured to provide posterior tibial slope. 